\title{
Alison Brayfield (Editor-in-Chief): Martindale, the complete drug reference. 38th edition
}

\author{
The pharmaceutical Press, London, 2014, ISBN: 9780857111395
}

\author{
J. W. F. van Mil
}

Published online: 25 September 2014

(C) Koninklijke Nederlandse Maatschappij ter bevordering der Pharmacie 2014

Over 5.6 kilo's of drug information on more than 4,500 pages in two volumes. The new edition of the Martindale has just appeared, under a new Chief Editor. For many pharmacists and pharmacy students internationally the Martindale is the reference for medicines. If a substance is used as a medicine, it can be found in the Martindale. Accessibility is a central issue of such reference books. Therefore it contains several indexes. The index of generic names is complete, the index of international brand names is almost complete (it can never be really complete). It also includes an index of manufacturers and, strangely enough, even a Cyrillic Index. There is no index (yet?) in other languages like Chinese, Japanese, Malay or Thai, although the proprietary preparation section includes China.

Apart from the new cover, the changes in this edition are the usual. New monographs have been added, existing monographs updated, and some sections have been restructured (diabetes mellitus management, porphyria).

The book was first published in 1883 under the title Martindale: The Extra Pharmacopoeia. I still can remember that it was only one volume. But now there are over 6,000 monographs and two volumes. The current Martindale contains information on drugs in clinical use worldwide, as well as selected investigational and veterinary drugs, herbal and complementary medicines, pharmaceutical excipients, vitamins and nutritional agents, vaccines, radiopharmaceuticals, contrast media and diagnostic agents, medicinal gases, drugs of abuse and recreational drugs, toxic substances, disinfectants, and pesticides. Each monograph gives not only physical and chemical information, but also information on therapeutic use and administration, kinetics and the preparations that contain the substance.

\section{Conclusion}

The Martindale is a true universal reference and its information wealth is unparalleled. It is not a book one would use every day in clinical pharmacy practice, but a pharmacist can also not live without. Although one can certainly understand why this reference work must be so expensive, the high price will be a barrier especially for colleagues in developing countries. It is in the interest of society in general that every pharmacist can consult this drug reference book when needed. Significantly cheaper access of the on-line version should therefore be considered, for instance for limited time periods or a limited number of searches.
Official price: $€ 581 / £ 459 /$ US $\$ 695$ (includes VAT. It can be wise to shop around!) Personal account for online access to the Martindale (through MedicinesComplete) costs $£ 270$ Euro annually.

J. W. F. van Mil ( $\square)$

Zuidlaren, The Netherlands

e-mail: jwfvmil@vanmilconsultancy.nl 